\title{
Effective posttransplant antitumor immunity is associated with TLR-stimulating nucleic acid- immunoglobulin complexes in humans
}

\author{
Yun Lin, ${ }^{1,2}$ Li Zhang, 1,2,3 Ann X. Cai, ${ }^{1}$ Mark Lee, ${ }^{4}$ Wandi Zhang, ${ }^{1}$ Donna Neuberg, ${ }^{5}$ \\ Christine M. Canning, 1,2,6 Robert J. Soiffer,2,6 Edwin P. Alyea, ${ }^{2,6}$ Jerome Ritz, 1,2,6 Nir Hacohen,4 \\ Terry K. Means, ${ }^{4}$ and Catherine J. Wu ${ }^{1,2,6}$

\begin{abstract}
${ }^{1}$ Cancer Vaccine Center, and 2Department of Medical Oncology, Dana-Farber Cancer Institute, Boston, Massachusetts, USA ${ }^{3}$ Key Laboratory of Transplant Engineering and Immunology, Ministry of Health, West China Hospital, Sichuan University, Chengdu, China. ${ }^{4}$ Division of Rheumatology, Allergy and Immunology, Massachusetts General Hospital, Boston, Massachusetts, USA. ${ }^{5}$ Department of Biostatistical Science Dana-Farber Cancer Institute, Boston, Massachusetts, USA. ${ }^{6}$ Department of Medicine, Brigham and Women's Hospital,
\end{abstract} \\ Harvard Medical School, Boston, Massachusetts, USA.
}

\begin{abstract}
Donor lymphocyte infusion (DLI), whereby donor mononuclear cells are infused into patients, is one of the few effective immunotherapeutic strategies that generate long-lasting tumor remissions. We previously demonstrated that chronic myelogenous leukemia (CML) patients treated with DLI develop high-titer plasma antibodies specific for CML-associated antigens, the majority of which have been reported to bind nucleic acids These observations led us to predict that circulating antibody-antigen complexes in DLI-responsive patients carry nucleic acids that can engage innate immune sensors. Consistent with this, we report here that post-DLI plasma from $5 \mathrm{CML}$ patients that responded to DLI treatment induced massive upregulation of MIP-1 $\alpha$, IP-10, and IFN- $\alpha$ in normal blood mononuclear cells. Importantly, this was not observed with plasma obtained before DLI and from DLI nonresponders and imatinib-treated patients. This endogenous immunostimulatory activity required nucleic acid and protein for its adjuvant effect and activated antigen-presenting cells through the RNA and DNA sensors TLR8 and TLR9. Presence of the immunoglobulin Fc receptor CD32 enhanced cellular responses, suggesting that immunoglobulins associate with this activity. Finally, a TLR-induced expression signature was detectable in post-DLI but not pre-DLI blood, consistent with an active circulating TLR8/9-stimulating factor. We have therefore demonstrated that effective tumor immunity correlates with the presence of endogenous nucleic acid-immunoglobulin complexes in patient plasma, thus providing a putative mechanism for the induction of potent antigen-specific immunity against malignant cells.
\end{abstract}

\section{Introduction}

Allogeneic hematopoietic stem cell transplantation can lead to several immunological outcomes, including graft-versus-host disease (GvHD) and graft-versus-leukemia effects (GvL) (1). The typical locations of GvHD reactions suggest that induction of this potent immune response may involve the presence of pathogen-derived adjuvants and antigens in pathogen-containing sites such as skin and gut (2). Less clear is how an immune response can be initiated against leukemia cells in the blood (i.e., GvL) where there is no obvious source of adjuvants. TLRs have emerged as critical initiators of immunity. Over a dozen TLRs have been identified, each with a defined ligand and unique expression patterns within and outside the immune system, especially on DCs, macrophages, and monocytes, where they serve to bridge innate and adaptive immunity (3). While TLRs were initially thought to be pattern recognition receptors for the exclusive sensing of microbial components, recent studies show that endogenous nucleic acid-immunoglobulin complexes circulating in lupus patients potently activate immune cells through nucleic acid-sensing TLRs and FcRs (4-13) and hence may play a role in the development of autoimmunity.

Authorship note: Yun Lin and Li Zhang contributed equally to this work. Conflict of interest: The authors have declared that no conflict of interest exists. Citation for this article: J Clin Invest. 2011;121(4):1574-1584. doi:10.1172/JCI44581.
To determine whether GvL is associated with the presence of endogenous blood-borne adjuvants, we have focused on a potent human example of tumor immunity, donor lymphocyte infusion (DLI), for the treatment of posttransplant relapsed chronic myelogenous leukemia (CML) $(1,14,15)$. In this procedure, donor mononuclear cells are infused into the patient, often in the absence of further chemotherapy or radiation, and $75 \%-80 \%$ of patients with relapsed CML achieve long-lasting remission. We previously identified potent antigen-specific antibody responses developing against leukemia antigens, at titers matching those against viral antigens following viral infection, appearing in close temporal relationship with antigen-specific $\mathrm{CD}^{+} \mathrm{T}$ cell responses and with elimination of tumor burden $(16,17)$. Similar to autoimmunity, we discovered that many target antigens of DLI-associated antibodies developing in GvL are intracellular and are enriched for nucleic acid-binding activities. These observations led us to hypothesize that the potent coordinated adaptive immunity associated with antitumor GvL responses may be partly driven by innate immune stimuli such as nucleic acids.

To explore this hypothesis, we tested plasma from patients with CML treated with DLI, who demonstrated GvL but not clinical GvHD, for their ability to stimulate PBMCs to produce proinflammatory cytokines. Herein, we report that these plasma samples can broadly activate a variety of immune cell populations ex vivo through TLR8 and TLR9, which are known to recognize nucleic 
Table 1

Patient characteristics

\begin{tabular}{|c|c|c|c|c|c|c|c|c|}
\hline Pt. & $\begin{array}{l}\text { Treatment for } \\
\text { relapsed CML }\end{array}$ & $\begin{array}{l}\text { Age/ } \\
\text { sex }\end{array}$ & $\begin{array}{c}\text { DLI cell dose } \\
\left(\times 10^{7} \mathrm{CD}^{+} \text {cell } / \mathrm{kg}\right)\end{array}$ & $\begin{array}{l}\text { Mo from } \\
\text { BMT to DLI }\end{array}$ & $\begin{array}{l}\text { Mo to molecular } \\
\text { response }\end{array}$ & $\begin{array}{l}\text { Mo to cytogenetic } \\
\text { response }\end{array}$ & $\begin{array}{l}\text { Infection after } \\
\text { therapy }\end{array}$ & $\begin{array}{c}\text { GVHD } \\
\text { after DLI }\end{array}$ \\
\hline A & DLI & $28 / F$ & 30 & 54 & 11 & 3 & No & Min \\
\hline B & DLI & $52 / F$ & 3 & 7 & 17 & 4 & No & No \\
\hline C & DLI & $40 / F$ & 3 & 26 & 3.5 & 3 & No & Min \\
\hline D & DLI & $38 / F$ & 3 & 42 & 7 & 2 & No & No \\
\hline$E$ & DLI & $47 / M$ & 3 & 37 & 3 & 2 & No & No \\
\hline $\mathrm{F}$ & DLI & $50 / F$ & 3 & 13 & UN & 6 & No & No \\
\hline G & DLI & $37 / M$ & 3 & 36 & UN & 8 & No & No \\
\hline $\mathrm{H}$ & DLI & $39 / M$ & 30 & 19 & UN & 10 & No & No \\
\hline I & DLI & $48 / \mathrm{M}$ & 3 & 18 & NR & NR & No & No \\
\hline J & DLI & $35 / F$ & 3 & 39 & NR & NR & No & No \\
\hline K & DLI & $50 / M$ & 3 & 11 & NR & NR & No & No \\
\hline $\mathrm{L}$ & DLI & $19 / M$ & 30 & 36 & NR & NR & No & No \\
\hline$M$ & Imatinib & $45 / \mathrm{M}$ & NA & NA & UN & 6 & No & NA \\
\hline N & Imatinib & $34 / \mathrm{M}$ & NA & $N A$ & UN & 4 & No & NA \\
\hline 0 & Imatinib & $65 / F$ & NA & NA & UN & 6 & No & NA \\
\hline$P$ & Imatinib & $55 / \mathrm{M}$ & NA & NA & UN & 7 & NA & NA \\
\hline Q & Imatinib & $66 / M$ & NA & NA & UN & 6 & NA & NA \\
\hline $\mathrm{R}$ & Imatinib & $59 / \mathrm{M}$ & NA & NA & UN & 6 & NA & NA \\
\hline S & DLI & $59 / F$ & 30 & 17 & 4 & 2 & No & Yes \\
\hline $\mathrm{T}$ & DLI & $51 / \mathrm{M}$ & 3 & 27 & UN & 3 & No & Yes \\
\hline U & DLI & $36 / M$ & 3 & 25 & UN & 3 & No & Yes \\
\hline
\end{tabular}

NR, no response; UN, information unavailable.

acids. The activity of factors was heightened when complexed with antibody and could be mimicked when testing nucleoprotein immune complexes (ICs) containing the DLI-associated antigen CML66. Implications of these findings for the development of productive antitumor vaccination strategies are discussed.

\section{Results}

Potent immunostimulatory activity is present in plasma of patients who demonstrate tumor rejection following DLI. In a clinical trial of $\mathrm{CD}^{+}$ DLI for patients with relapsed hematologic malignancy following allogeneic stem cell transplantation, we observed the frequent achievement of robust GvL responses with low rates of GvHD in patients with relapsed CML (15). The current study focuses on the dissection of immune responses in 8 study subjects, patients $\mathrm{A}-\mathrm{H}$, all of whom achieved durable remission following DLI for relapsed CML in the absence of clinically significant GvHD. As shown in Table 1, these patients represent a clinically homogenous group of patients: all demonstrated relapsed disease following T cell-depleted myeloablative transplant for stable phase disease, and all were subsequently treated with an infusion of 3-30 $\times 10^{7}$ donor-derived $\mathrm{CD}^{+}$cell $/ \mathrm{kg}$ in the absence of further chemotherapy or radiation. In response to DLI, all patients achieved cytogenetic remission at a median of 3.5 months and molecular remission (defined as BCR-ABL negative by PCR) at 9 months. None experienced concurrent infections nor greater than grade $1 \mathrm{GvHD}$ (and hence did not require systemic corticosteroid treatment) during the months following infusion of donor lymphocytes.

To begin to dissect the components contained within patient plasma that could contribute to potent antitumor GvL responses, we first examined the cytokine and chemokine profiles generated in PBMCs of normal volunteers following exposure to post-DLI plasma from patients A-E compared with either plasma collected from the same patients prior to DLI treatment or from normal volunteers. Following incubation with media containing 20\% patient plasma, we detected impressive evidence of immune stimulation of PBMCs, measured by the de novo production of 15 individual cytokines/chemokines using a sensitive quantitative PCR assay. As demonstrated in the representative results shown in Figure 1, a 3-hour exposure to plasma from patients D and $\mathrm{E}$ resulted for each production of a broad array of cytokines and chemokines by PBMCs. Exposure of normal volunteer PBMCs to plasma collected from patients at approximately 3 months following DLI, when cytogenetic responses to DLI are typically first observed, resulted in a 3- to 50-fold increase in the production of MIP-1 $\alpha$ (CCL3), MIP-1 $\beta$ (CCL4), MCP-1 (CCL2), MIP-3 $\alpha$ (CCL20), TNF, IL-8 (CXCL8), IFN- $\alpha$, and GRO $\alpha$ (CXCL1). Even further increases in the expression of these cytokines and chemokines from normal volunteer PBMCs were observed following stimulation with plasma collected 8 months after DLI and at the time of complete molecular responses, suggesting the presence of ongoing immunologic activity. In contrast, exposure of PBMCs to control plasma (20\% fetal calf serum) or to plasma collected from the same patients prior to DLI or from normal donors resulted in only minimal production of cytokine/chemokine transcripts.

To determine whether this immunostimulatory activity was uniquely observed in patients who demonstrate clinical antitumor immune responses to DLI, we compared these results with responses of normal volunteer PBMCs exposed to plasma from patients who had undergone DLI but without clinical response (patients I-K; Table 1) and patients treated with an effective nonimmune-based therapy for CML, imatinib mesylate (patients M-R, Table 1), who demonstrated clinical responses to therapy within the same time range as the DLI-treated patients A-E. Of the 15 cytokines and chemokines assessed, we observed the clearest dif- 

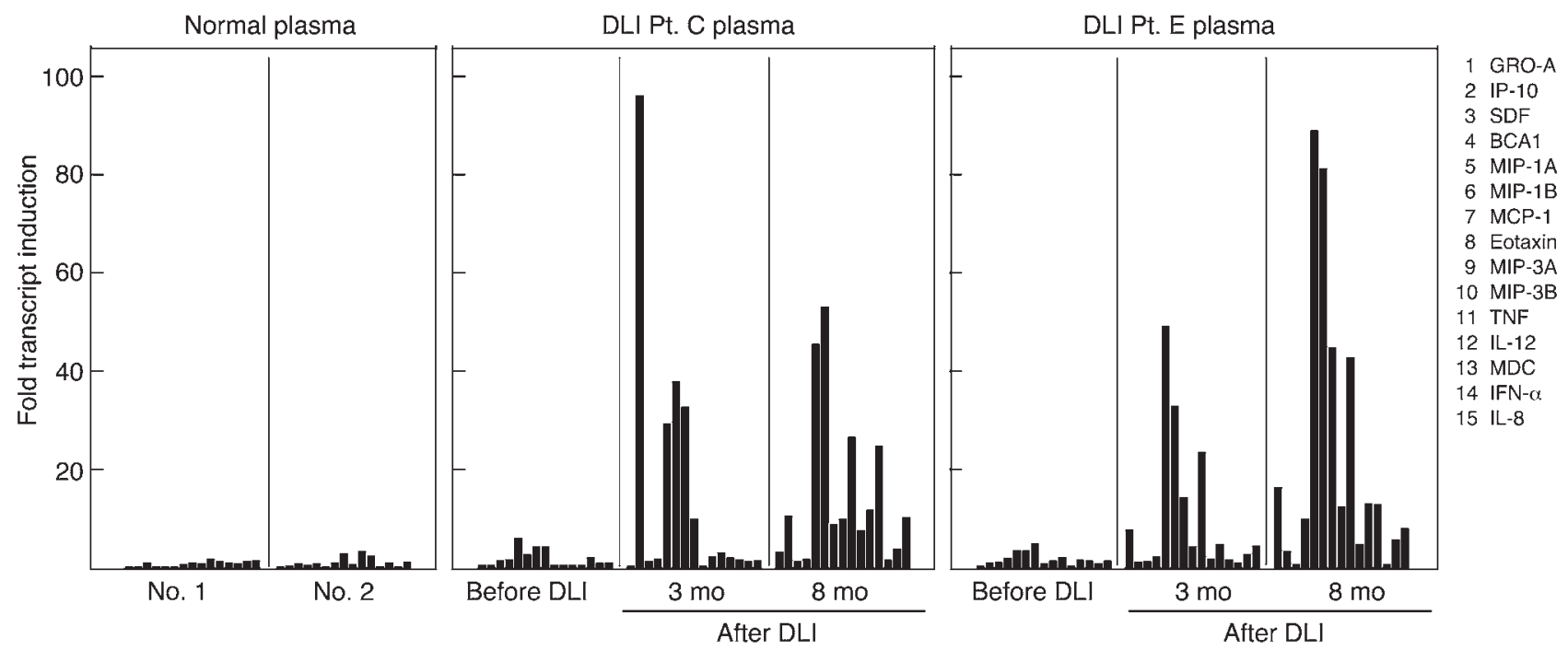

Figure 1

CML DLI responder plasma stimulates the transcription of a wide range of proinflammatory cytokines and chemokines. PBMCs derived from normal volunteers were cultured in the presence of $20 \%$ plasma derived from normal donors or from DLI responder patients before and 3 or 8 months following infusion of donor lymphocytes. Following 3 hours of incubation, RNA was extracted from the PBMCs and tested for the presence of an array of cytokines and chemokines. All quantitative PCR tests were concurrently run with GAPDH to control for RNA quality. Representative results generated from 2 of $5 \mathrm{DLI}$ responders are presented as fold increase in transcript expression over the control (cells stimulated with $20 \%$ fetal bovine serum alone). Fold transcript induction of the 15 cytokines and chemokines tested is depicted per sample in the order provided by the list of analytes on the far right side of the figure. Pt., patient.

ferences when examining MIP-1 $\alpha$, IP-10 (CXCL10), and IFN- $\alpha$. Prior to transplant, MIP- $1 \alpha$ and IFN- $\alpha$ were significantly higher for DLI responders compared with nonresponders or with imatinib-treated patients $(P=0.036$ each). As shown in Figure 2, all 5 DLI patients demonstrated increases in the expression of IP-10, IFN- $\alpha$, TNF- $\alpha$, and MIP- $1 \alpha$ at both early ( 3 months) and late (8 months) time points following DLI, which was not observed in 3 of 3 CML DLI nonresponders, nor 3 of 3 responders of imatinib mesylate. Significant differences were observed between responders and nonresponders at 8 months $(P=0.036,0.034$ and 0.07 for MIP-1 $\alpha$, IP-10, and IFN- $\alpha$ ) and between DLI responders and imatinib responders $(P=0.032,0.008,0.008$, and 0.006 for MIP- $1 \alpha$, IP-10, IFN- $\alpha$, and TNF- $\alpha$ ). While these results are consistent with the involvement of the IFN pathway in GvL responses, the production of these 4 cytokines/chemokines is not restricted to a single signaling pathway and suggests the possible involvement of multiple effector cell populations.

Post-DLI responder plasma stimulates multiple types of antigen-presenting cells. To define the immune populations that respond to stimulation by DLI plasma (i.e., normal B cells, T cells, NK cells, plasmacytoid DCs [pDCs], and myeloid DCs [mDCs] and monocytes), we purified each immune cell subpopulation from peripheral blood of normal volunteers, briefly stimulated each with plasma collected from patients $\mathrm{A}-\mathrm{C}$ and $\mathrm{E}$ prior to and after DLI, and then tested each for de novo cytokine/chemokine production by quantitative RT-PCR (qRT-PCR). Results from all 4 experiments are shown in Figure 3.

As shown in Figure 3, the predominant responding cell subpopulation varied from individual patient to patient. Compared with pretreatment plasma, exposure to plasma collected following DLI resulted in increased expression of cytokines such as IP-10, IFN- $\alpha$, TNF- $\alpha$, IL- $1 \beta$, IFN- $\gamma$, IL-12, and others in monocytes, B cells, pDCs, mDCs, and NK cells - each cell populations known to bridge innate and adaptive immunity. In contrast, T cells, which reside squarely within the adaptive immune system, rarely demonstrated increased expression of cytokine or chemokine transcripts following exposure to post-DLI plasma.

Post-DLI plasma stimulates TLRs that respond to nucleic acids. When we pretreated post-DLI plasma with DNase, RNase, papain, or pepsin, we observed a $40 \%-50 \%$ decrease in induction of expression of IL-8 from normal monocytes compared with untreated plasma (Figure 4A). Induction of cytokine expression decreased even further following pretreatment with DNase and pepsin together. These results strongly suggested that the endogenous immunostimulatory activity contained within patient plasma comprised both nucleic acid and protein. The known ligands of several TLR receptors are nucleic acids. We therefore directly tested the ability of patient plasma to stimulate specific TLRs by using TLR-expressing stable transfectants. These transfectants are human embryonic kidney (HEK) cells, stably transfected with different individual TLR constructs, including TLR3, TLR4, TLR8, and TLR9 (18). In a fashion similar to that used in our PBMC-based experiments, we briefly incubated these TLR-expressing transfectants with patient plasma and subsequently analyzed the cells for induction of cytokine/chemokine RNA expression. As these transfectants are epithelial cells that do not express TLRs at baseline, they do not possess the cellular machinery to express most cytokines, with the exception of IL-8. Thus, the readout for TLR activation in this system is IL-8 transcript expression, which we quantified by qRT-PCR (10). As shown in Figure 4B, each of the 4 cell lines secreted IL- 8 in response to the corresponding agonist, and none of the 4 were reactive when exposed to plasma from a series of normal adult volunteers.

When the various TLR-expressing transfectants were stimulated with plasma from DLI responders, collected 3-6 months after DLI response, we observed that IL-8 expression was induced from 3 of 4 
Before DLI plasma
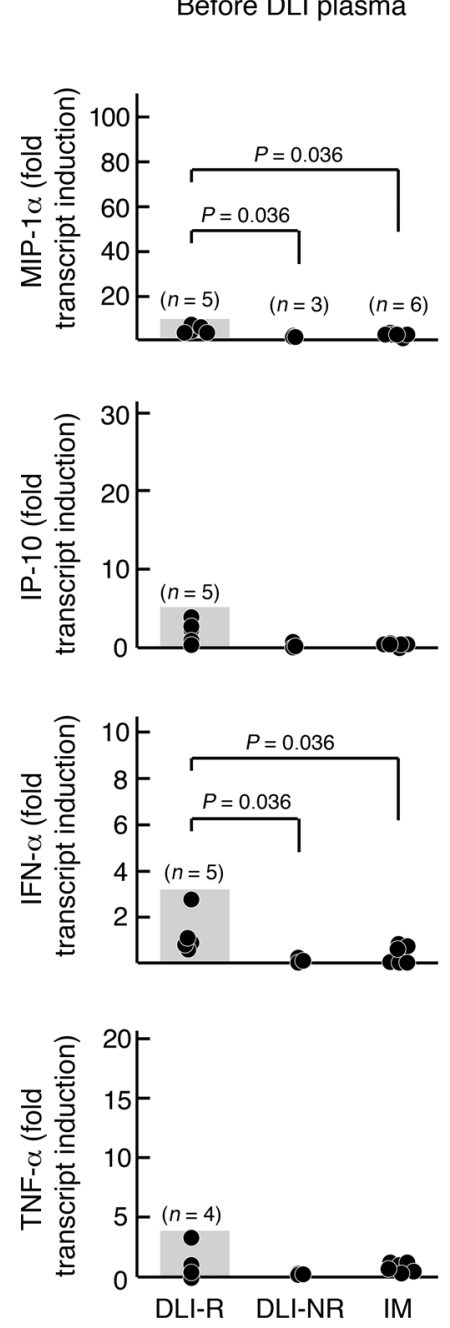

3-mo plasma
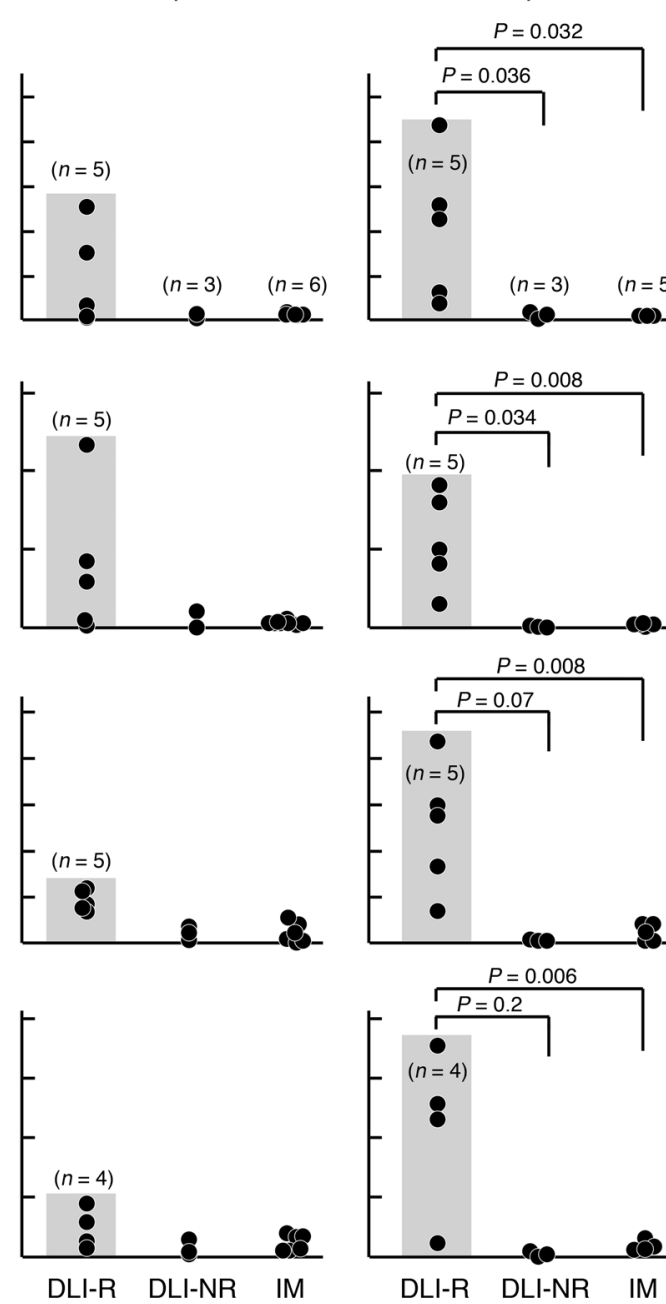
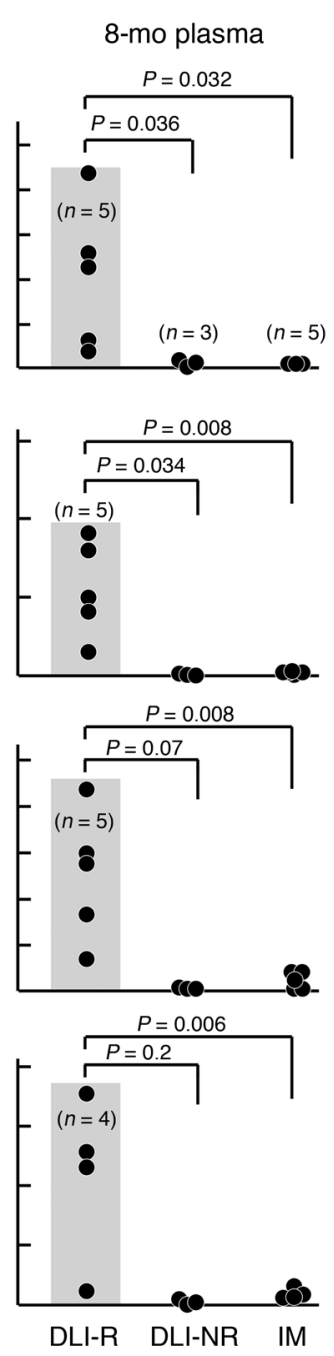

Figure 2

Plasma from CML DLI responders (DLI-R, $n=5$ ), but not from CML DLI nonresponders (DLI-NR, $n=3$ ), nor patients treated with imatinib (IM) $(n=6)$ stimulate induction of expression of MIP- $1 \alpha$, IP- 10 , and IFN- $\alpha$ from normal allogeneic PBMCs. Significance was calculated using the Wilcoxon's rank sum test. Data points represent individual patients.

while IgG ICs isolated from patient B increased reactivity (Figure 4C). Taken together, these results suggested that the nature of the TLR8- and TLR9-stimulating activity is an IC consisting of nucleic acid bound to antibody. In support of these findings, we detected nucleic acid in plasma of 3 of 3 DLI patients (patients F, $\mathrm{E}$, and $\mathrm{C}$ ) and also in plasma-derived ICs isolated from these patients (Figure 4E).

CML66 ICs can activate TLR9. More than half of the candidate antigens identified in our previous antibody-based screens for targets of DLI-induced immunity demonstrated selective or elevated expression in CML progenitor cells and have known binding activity to nucleic acids $(16,19$, 20). These characteristics together with our current data suggested that nucleic acids complexed to these antigens could potentially activate TLRs. If so, this property could be important for stimulating immunity against malignant cells with self-renewing capacity. We therefore examined the TLR-activating ability of ICs to CML66. This is an intracellular leukemia-

samples in TLR8-expressing cells and from 3 of 5 plasma samples in TLR9-expressing cells (Figure 4B). In contrast, 0 of 5 plasma samples induced IL-8 expression from the TLR3- and TLR4expressing transfectants. Since both TLR8 and TLR9 are known to be activated by single-stranded RNA and double-stranded DNA, respectively, these data suggested that patient plasma contains immunostimulatory nucleic acid.

The endogenous immunostimulatory factor in DLI plasma requires both nucleic acid and protein for its adjuvant activity. To better characterize the plasma components responsible for TLR activation by patient post-DLI samples, we tested vector-transfected cells, TLR8- and TLR9-expressing cells, and cells expressing TLR8 or TLR9 together with CD32 (FcyRIIa). As shown in Figure 4D, plasma from 3 DLI patients contained activating factors for TLR9, whose activity was further enhanced by 2- to 4-fold when the transfectants coexpressed CD32. Consistent with the notion that TLR9 recognizes dsDNA, plasma pretreatment with DNase completely abrogated IL-8 induction in both the TLR9-expressing and TLR9/CD32expressing transfectants. On the other hand, IgG ICs directly isolated from patient plasma further enhanced activation on the cell lines. In an analogous fashion, in experiments performed with TLR8 transfectants, pretreatment of patient A DLI plasma with RNase abrogated induction of IL-8 expression (data not shown), associated antigen that elicits high-titer $\mathrm{B}$ cell and $\mathrm{CD}^{+} \mathrm{T}$ cell responses early after DLI in association with leukemia regression (17). While the exact cellular function of CML66 is unknown, it has been implicated in cell survival and proliferation (21). To favor the generation of CML66-specific antigen ICs that could still bind nucleic acid, we immunoprecipitated CML66 from gently lysed K562 cells (a BCR-ABL ${ }^{+}$CML cell line) using a CML66-specific monoclonal antibody (22). The isolated ICs were then tested for TLR activation on TLR9-expressing HEK cells. As shown in Figure 5A, CML66 could activate TLR9-expressing cells upon exposure to CML66 immunoprecipitated from CML cell lysates compared with ICs generated by irrelevant isotype controls (anti-actin and anti-CD3 antibodies). These CML66-ICs could also stimulate 2- to 3 -fold greater IL-8 expression in human monocytes in a DNase- and papain-sensitive fashion than control ICs (Figure 5B). In support of these experiments, we detected nucleic acid in the CML66-associated ICs isolated from K562 cell lysates (Figure 5C). Altogether, these experiments demonstrate that individual leukemia-associated antigens can possess endogenous adjuvant-like activity that stimulates innate immunity and may thus initiate and enhance GvL.

Activation of TLR8 and TLR9 occur early in the post-DLI period, preceding initiation of leukemia-antigen-specific antibody responses. To determine whether presence of these endogenous TLR-activating 


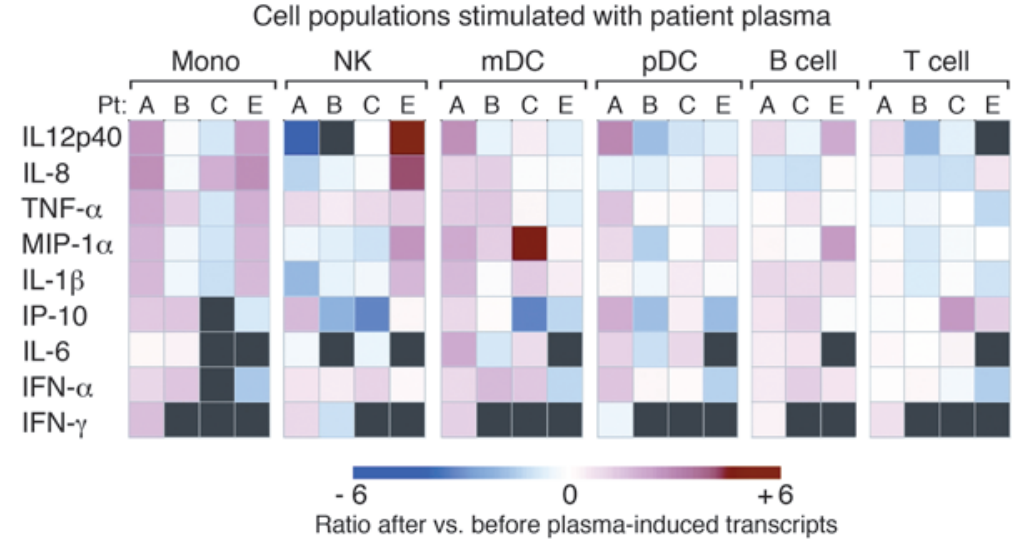

\section{Figure 3}

Post-DLI responder plasma stimulates cells that bridge innate and adaptive immunity. Results of 4 experiments are shown, in which we found that plasma from CML DLI responders is immunostimulatory to monocytes, B cells, DCs, and NK cells, with minimal effect on mature T cells. Purified cell populations derived from normal PBMCs were incubated with $20 \%$ patient plasma, and cytokine/ chemokine transcript levels when stimulated with postDLI compared with pre-DLI plasma were quantified relative to GAPDH transcripts. Data were $\log _{2}$ transformed and visualized the JColorGrid javascript module. Dark gray squares represent absent data. stimuli are temporally correlated with DLI-associated adaptive immunity and tumor eradication, we tested plasma collected from patients at various times following DLI on the TLR-expressing cell lines. As shown in Figure 6, plasma from DLI nonresponders (4 patients tested), from DLI-treated patients who developed GvHD (8 patients tested), or from imatinib-treated patients (7 patients tested) across multiple time points did not result in greater than 1- to 2 -fold increased IL-8 expression compared with stimulation with pretreatment plasma on TLR-expressing HEK cells than on nontransfected HEK cells.

However, starting as early as 2 weeks after DLI, through at least 15 to 20 weeks after DLI, we observed evidence of TLR stimulatory capacity in plasma of DLI responders (Figure 6; patients A and C shown, out of 4 patients tested). For patient C, using plasma collected 4 weeks after DLI, we observed peak stimulation of TLR9 and -8 at 3- to 10 -fold over control, respectively, that was modestly increased in the presence of CD32. Following 15-20 weeks, this stimulatory capacity waned. For patient A, we similarly observed peak responses between 8 to 12 weeks following DLI. In this patient, we observed marked enhancement of TLR9 stimulation in conjunction with CD32 coexpression, suggesting that antibody complexes likely played a contributory role in post-DLI immunity in this individual. Of note, this peak in TLR9/CD32 stimulation coincided with the induction of detectable antigen-specific antibody responses to CML antigens in patient $\mathrm{A}$ (previously described ref. 16). CD32 is unlikely to enhance TLR8 or TLR9 signaling without the need for ligation, since TLR8 and TLR9 signaling by conventional ligands (CPG, R848) is not enhanced in the presence of CD32 (Supplemental Figure 2; supplemental material available online with this article; doi:10.1172/JCI44581DS1).

In vivo evidence of TLR activation following DLI in patients with antileukemia responses. Since the previous data demonstrate that patient plasma activates TLR pathways ex vivo, we sought to examine the activation of these pathways in vivo. Based on the cytokine/chemokine signature following in vitro treatment (Figure 2), we directly examined evidence for such a signature in unmanipulated, banked PBMC samples collected from the DLI-treated patients. Consistent with our in vitro experiments, we observed an increase in the expression of IP-10, TNF- $\alpha$, IL-8, and MIP1 $\alpha$ (but not IFN- $\alpha$ ) transcripts in the first 2 months following DLI in 5 of 5 DLI responders (Figure 7). This peak in cytokine/chemokine expression preceded development of cytogenetic remission and was concurrent with development of $\mathrm{T}$ cell and antibody responses (previously characterized in refs. 16,17). The signature was not observed in 2 non- responding DLI-treated patients. By quantitative expression profiling of innate immune response genes in PBMCs derived from patient $\mathrm{A}$, we found a striking elevation in the global inflammatory signature concomitant with a reduction in the viral signature at early time points after DLI. As shown in Figure 8, the expression of 33 of 86 genes was upregulated following DLI, while 52 genes demonstrated consistent downregulation following DLI. Of the 33 upregulated genes, 12 were classified, with 11 of 12 belonging to the inflammatory response (i.e., response to bacterial ligands; refs. $23,24)$. In contrast, 12 of the 15 classifiable and downregulated genes belong to the viral signature. Confirming this discovery, we performed qRT-PCR) on 3 inflammatory pathway genes (CXCL1, CXCL3, IL6) and 3 viral pathway candidates (DDX58, IFNB1, IRF7) on PBMCs from 2 independent DLI responders (patients F and G) and 1 DLI nonresponder (patient K). As shown in Figure 8B, gene expression of CXCL1, CXC3, and IL- 6 was generally elevated within PBMCs of both DLI responders but not the nonresponder. Conversely, gene expression of the 3 viral pathway genes were relatively lower compared with the inflammatory pathway genes in the 2 DLI responders and markedly higher in expression for 2 of the 3 genes in the nonresponder.

\section{Discussion}

TLRs have emerged as critical receptors for the initiation of productive immune responses (25). Our current studies now suggest that this important pathway also contributes to the generation of productive antitumor immune responses in vivo. We present evidence that therapy-induced antitumor immune responses are associated with the production of endogenous adjuvants, present in plasma of reactive patients, in the form of nucleic acid-antibody complexes, whose activity can be abrogated by endonucleases and peptidases. In support of the contributing role of these endogenous adjuvants in stimulating and enhancing GvL, we observed detectable TLRactivating activity as early as 2 weeks following DLI, preceding the development of high-titer antibodies (which we previously demonstrated to start at $2-3$ months after DLI $(16,20)$. Furthermore, the cytokine signature associated with TLR activation was detected directly in vivo from patients with productive immune responses. TLR activation was not detected before DLI, nor in normal donors, nonresponders of DLI, DLI-treated patients who developed GvHD, nor in pharmacologically treated patients (in which immunity is not thought to be the basis of antitumor activity). These studies provide what we believe is a novel mechanism by which effective antileukemia immunity is initiated and propagated in vivo. 
A
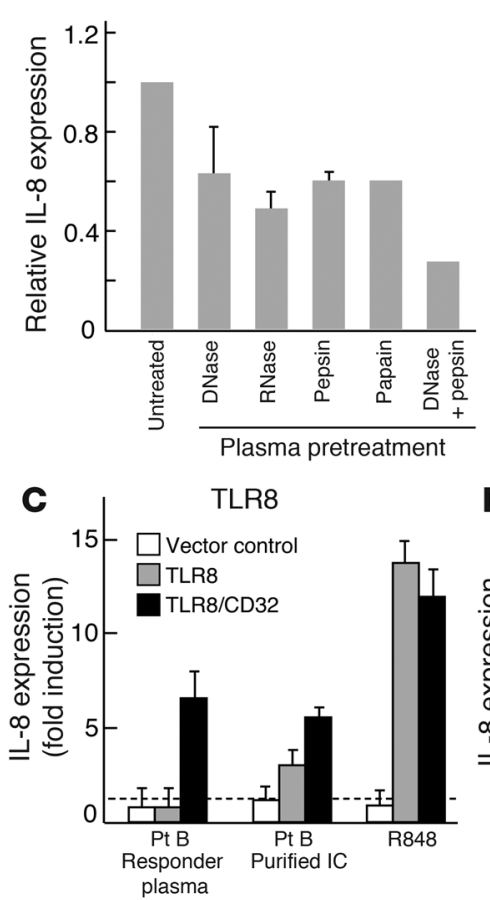

B

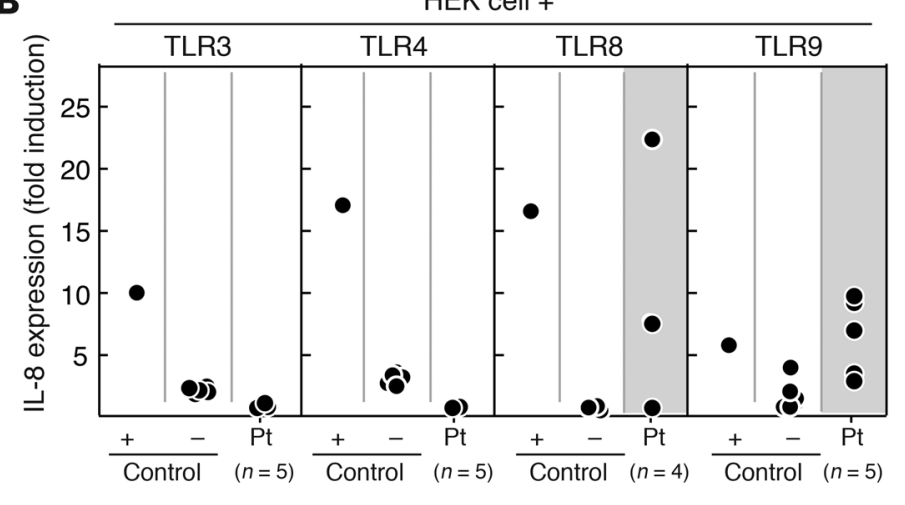

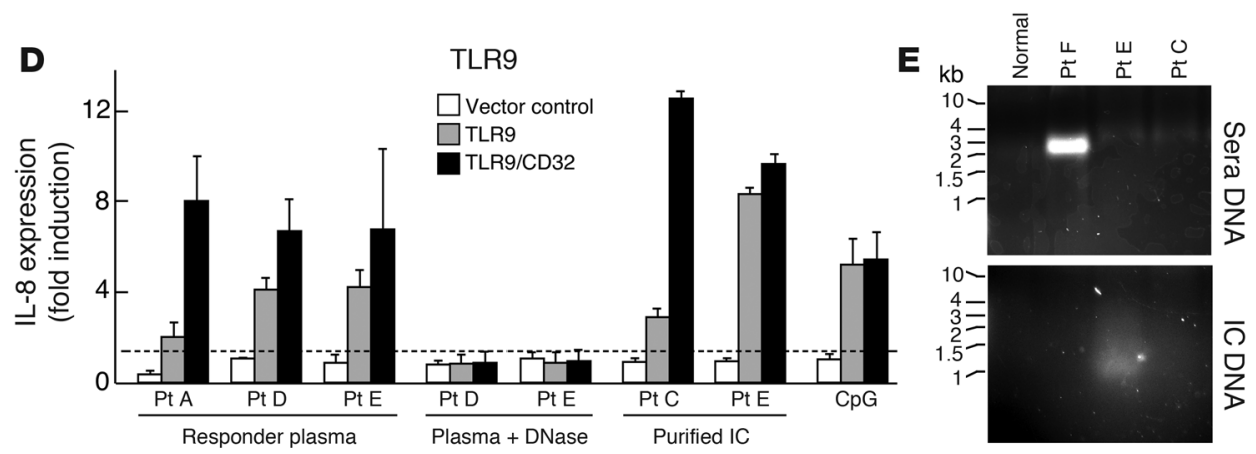

Figure 4

Post-DLI plasma stimulates TLRs that respond to nucleic acid. (A) Stimulation of IL-8 expression from monocytes is dependent on presence of DNA, RNA, and protein in the plasma. This figure summarizes results of 5 experiments (mean \pm SEM). (B) Plasma from CML patients responsive to DLI therapy stimulates IL-8 production from HEK cells that are stably transfected with TLR8 and TLR9 (shaded), but not with TLR3 or TLR4. Negative controls were HEK transfectants stimulated with plasma from normal adult volunteers. Positive controls were HEK transfectants stimulated with TLR agonists. (C) Post-DLI plasma or ICs derived from post-DLI plasma were tested against control, TLR8-expressing, and TLR8/ CD32-expressing transfectants. Cell lines were also tested against the known TLR8 agonist R848. Data shown represent mean values \pm SEM. (D) Post-DLI plasma was tested against control, TLR9-expressing, and TLR9/CD32-expressing transfectants. DNase abrogates TLR9 stimulatory activity, while purification of IC enhances immunostimulatory activity. Cell lines were also tested against the known TLR9 agonist CpG. Data shown represent mean values \pm SEM. (E). Plasma nucleic acid from DLI responders and a normal volunteer were extracted using phenol-chloroform and visualized by ethidium bromide-staining of a 1.0\% agarose gel. ICs from the same subjects were isolated using Protein G beads. IC-associated nucleic acid was visualized by GelRed on a $1.0 \%$ agarose gel following heat disassociation from beads $\left(65^{\circ} \mathrm{C} \times 5\right.$ minutes).

Our results mirror recent findings in murine models that efficacy of DLI-induced antitumor responses are improved with the coadministration of TLR ligands (26). In contrast, administration of TLR agonists concurrent with conditioning chemoradiation and stem cell infusion appears to aggravate graft rejection and GvHD (27) and underscore the critical importance of timing of adjuvant exposure together with its interaction with other immune-activating stimuli to determine the direction of clinical outcome (28). By comparison to patients with GvL responses, plasma of patients with GvHD was not immunostimulatory using our detection assays. This could reflect the fact that GvHD reactions predominantly occur at local tissue sites. In addition, we observed that GvL plasma was immunostimulatory to many immune cell populations, but not B cells, while She et al. have described increased responsiveness of B cells of patients who developed GvHD to TLR9 (29).

A hallmark of effective immune responses following allotransplant and DLI is the development of polyclonal T and B cells reactive against multiple leukemia antigens and alloantigens (2). Our analysis of TLR activation in the DLI setting now provides us with a model for how this complex antigen-driven process can be initiated and amplified. We present evidence that ICs against an individual leukemia-associated antigen, CML66, can activate TLR9. This finding is of particular interest since we only found high CML66-specific T cell responses developing after DLI, when antigen-specific antibodies were present, despite the detection of marrow-resident $\mathrm{CD}^{+} \mathrm{T}$ cells with specificity for CML66 but with poor functional capacity in the patient prior to DLI therapy (at relapse). Thus, our studies support the concept that the "immunologic help" provided by DLI includes endogenous adjuvants that can stimulate $\mathrm{CD}^{+} \mathrm{T}$ cells to become effective. TLR activation is additionally known to be important for B cell activation, suppression of regulatory $\mathrm{T}$ cells, cross-presentation, and enhancement of the activities of antigen presenting cells in animal models (3, $30-40$ ). Pasare et al. showed that generation of productive cellular immune responses requires colocalization of antigen and TLR ligand within the same cellular compartment (36). We thus speculate that the development of antigen-specific antibody responses provides a forward activation loop to support and promote polyclonal responses through interaction with the Fc $\gamma \mathrm{R}$, to simultaneously deliver antigen and nucleic acid adjuvant to the same 


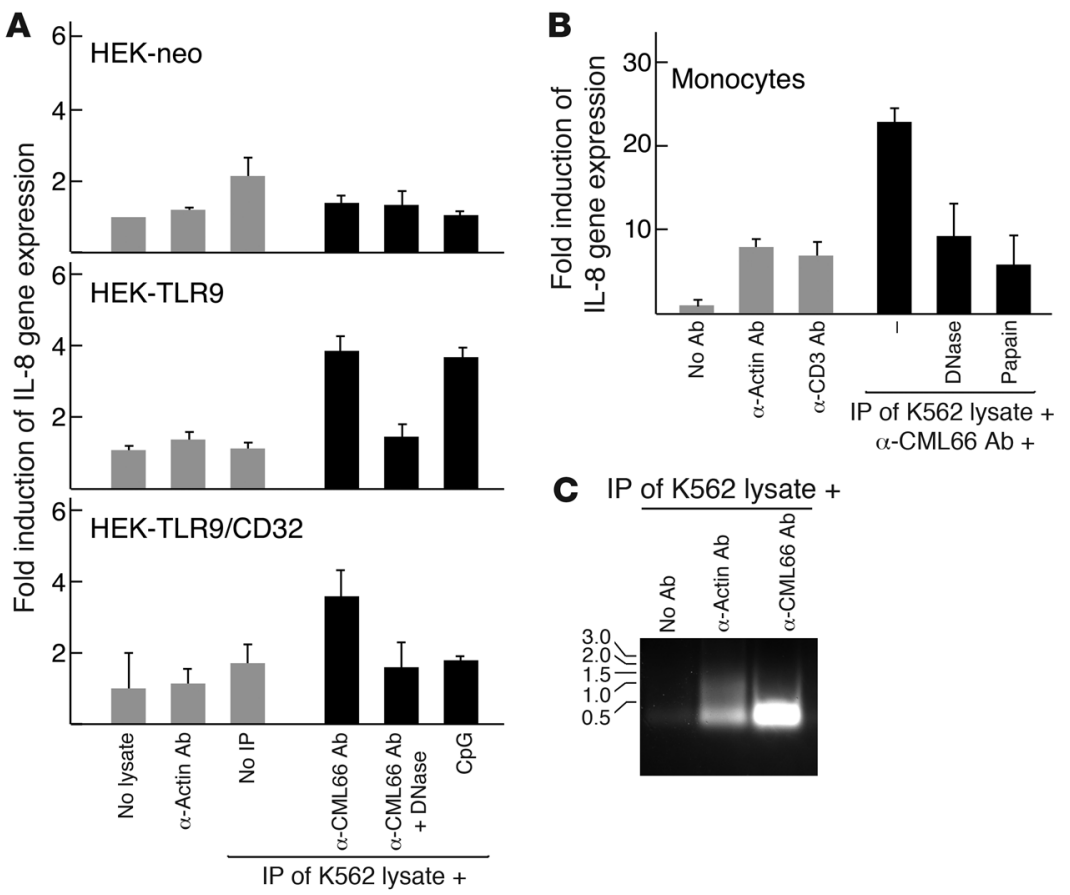

Figure 5

Stimulation of IL-8 expression by CML66-associated ICs requires both nucleic acid and protein in (A) HEK cells, transfected with vector (HEK-neo), TLR9, and TLR9/CD32 (mean results \pm SEM from 3 separate experiments), and in (B) normal monocytes (mean results \pm SEM from 5 experiments). ICs (black bars) were isolated from K562 lysates by immunoprecipitation with anti-CML66 $\mathrm{mAbs}$ or isotype control mAbs (anti-actin and antiCD3), isolated with Protein G-coated magnetic beads. IL-8 expression was measured by qRT-PCR of HEK cell-derived or monocyte-derived total RNA after a 3-hour incubation with ICs. (C) CML66 ICbound DNA/RNA was isolated by phenol-chloroform extraction from K562 lysate immunoprecipitated with anti-CML66 antibody (compared with control anti-actin antibody) and Protein G sepharose beads. The isolated nucleic acid was visualized on $1.0 \%$ agarose gel with ethidium bromide staining. subcellular compartment - the endosome - where TLR7/8 and TLR9 are located. To the extent that these antigens are also highly expressed in malignant CML progenitor cells, as we have described for CML66 and several DLI-associated antigens, these responses can be enhanced in a tumor-specific manner.

From where do these immunostimulatory nucleic acids, present in plasma of DLI-treated patients, originate? Over 20 years ago, greater levels of nucleic acid were detected in plasma of cancer patients compared with normal healthy controls (41-43). More recently, it has been appreciated that much of this nucleic acid is derived from tumor, rather than normal tissue, through apoptosis and/or tumor necrosis (44). We now demonstrate that plasma nucleic acid can be immunostimulatory. Different forms of immunogenic death have been described $(45,46)$. Conceivably, different malignancies may undergo different modes of death that lead to varied accessibility to immunogenic nucleic acid that can "prime" the generation of immune responses. Our study has focused on TLR-induced immunity, but increasingly diverse nucleic acid-sensing pathways have been identified that could also play roles in vivo in generating antitumor immune responses (47-49). We speculate that in the setting of allotransplant, extracellular release of leukemia antigens associated with immunostimulatory nucleic acid could occur shortly following DLI due to immediate leukemia cell cytolysis arising from alloreactivity to initiate a cascade of immune activation. While we cannot exclude that this activity is CML specific (the most immune responsive of all malignant hematologic diseases), we have observed similar elevated immune stimulatory activity in the plasma of patients successfully treated with DLI for myeloma (ref. 50 and see Supplemental Figure 3). TLR activation has been described to play a role in other leukemias, such as chronic lymphocytic leukemia (51), so the broader generalizability of the current findings is probable.

Since we do not know which combination of TLRs are activated at which times, it is difficult to predict the set of genes affected and their kinetics. From published studies, there are differential responses to TLR combinations in human cells for both inflammatory (IL-1 $\beta$, etc.) and viral (e.g., IFNB1, IRF7, OAS) genes (52). In addition, negative feedback pathways are activated in response to TLR ligation and shut off responses to TLRs; which negative feedback pathways are active over time in vivo is not known (23). In short, in vivo TLR responses over long periods of time are not possible to predict based on shortterm in vitro responses. Nevertheless, our results show that many of the TLR-responsive genes are indeed dysregulated in vivo, in support of the hypothesis that TLR pathways are activated after DLI.

The mechanistic insights gained from our study of GvL responses following DLI can be readily translated into generating more effective leukemia vaccination strategies. The vast majority of vaccine studies that incorporate TLR agonists have focused on single TLR adjuvants, while our studies suggest that effective responses commonly utilize multiple TLR-activating pathways with minimal toxicity. The antitumor effectiveness and low toxicity of employing multiple TLR agonists for vaccination has been supported by recent animal studies (53). Our studies further highlight the potential in vivo importance of antigen-specific antibodies in efficiently delivering immunostimulatory nucleic acids to activate TLRs. One potential area for future study will be to explore the combination of TLR8 and TLR9 agonists coupled together with leukemia-associated antigens that are endosomally delivered to efficiently stimulate leukemia-specific immunity.

\section{Methods}

Patient samples. Heparinized blood was obtained from normal volunteers and patients enrolled on IRB-approved protocols at the Dana-Farber Cancer Institute (DFCI), including clinical trials of DLI for the treatment of relapse after allogeneic BM transplant (BMT) following patients' informed consent (15). In these trials, lymphocytes were collected from the original BM donors by leukapheresis, and mononuclear cells were isolated by density gradient centrifugation using Ficoll-Hypaque. $\mathrm{CD}^{+} \mathrm{T}$ cells were depleted from the donor mononuclear cell fraction through 2 cycles of incubation with anti-CD8 monoclonal antibody (MoAb; DFCI2T8, IgG antibody) and rabbit complement. Aliquots of mononuclear cells obtained before and after CD8 deple- 

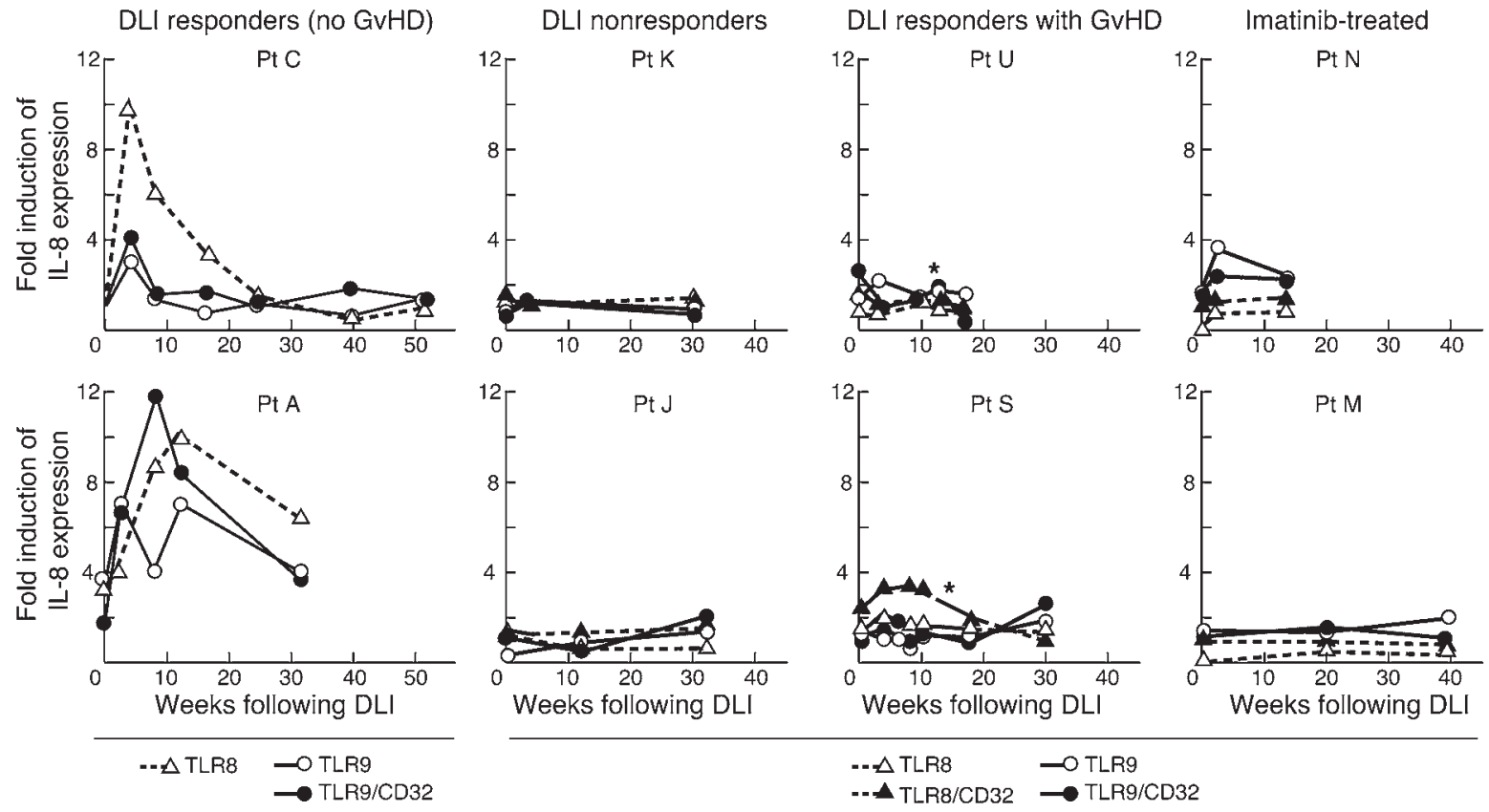

Figure 6

TLR8- and TLR9-stimulating activity is observed in CML patients who developed cytogenetic remission following DLI in the absence of systemic GVHD, but not in DLI nonresponders, DLI-treated patients who developed GvHD, or imatinib-treated patients. Stimulation was measured by IL-8 production in TLR-expressing transfectants compared with empty transfectants. Asterisks denote time points during which GvHD was diagnosed.

tion were analyzed for reactivity using fluorochrome-conjugated anti-CD4 and anti-CD8 monoclonal antibodies (Coulter Corp.) by flow cytometry (see Supplemental Table 1). PBMCs were isolated from whole-blood specimens collected from study subjects by Ficoll-Hypaque density gradient centrifugation (Sigma-Aldrich), cryopreserved in 10\% DMSO, and stored in vapor-phase liquid nitrogen until further use. Plasma was isolated following centrifugation of whole blood and cryopreserved at $-80^{\circ} \mathrm{C}$ until the time of analysis.

Isolation of immune cell populations. From 200-500 million mononuclear cells isolated from leukopacks collected from normal adult volunteers, primary human pDCs (BDCA-4 $4^{+}$, human mDCs $\left(\mathrm{BDCA1}^{+}\right)$, NK cells $\left(\mathrm{CD} 56^{+}\right)$, $\mathrm{B}$ cells $\left(\mathrm{CD} 19^{+}\right)$, and $\mathrm{T}$ cells $\left(\mathrm{CD}^{+}\right)$were purified by positive immunomagnetic bead selection (Miltenyi Biotec). Monocytes (CD14+) were negatively isolated by Rosette-sep (STEMCELL Technologies Inc.). Typical cell number yields following isolation ranged from 1 to 3 million cells (for pDCs and mDCs) to 20 to 30 million B cells, and 30 to 50 million T cells, NK cells, and monocytes. Greater than $85 \%$ purity of each of the isolated cell populations was confirmed by flow cytometry (see Supplemental Figure 1).

TLR transfectant cell lines and TLR agonists. HEK cells stably expressing TLR3, MD-2/TLR4, TLR9, or TLR9/CD32 were used, as previously described (10, 18). HEK cell lines stably expressing TLR8/HA were purchased from InvivoGen. Transient transfection of TLR8 cell lines to coexpress CD32 (CD32CFP/pcDNA3; gift of T. Means, Massachusetts General Hospital) was performed using Lipofectamine 2000 (Invitrogen), per the manufacturer's recommendations. Reagents used to confirm the TLR specificity of each cell line included poly(I:C) $(50 \mu \mathrm{g} / \mathrm{ml}$; Amersham Bioscience) for TLR3; LPS (10 ng/ml; Sigma-Aldrich) for TLR4; R848 (0.1 $\mu \mathrm{M}$; gift from 3M Company and Graceway Pharmaceuticals LLC) for TLR8; and CPG oligonucleotide (5-10 $\mu \mathrm{M}$, ODN2006G; InvivoGen) for TLR9.

Detection of de novo and ex vivo cytokine and chemokine production. qRT-PCR was used to detect a broad array of cytokines and chemokines, using genespecific sense and anti-sense primers, as previously described (10). In exper- iments using PBMCs or purified cell populations, 0.5 to 1 million cells in suspension were stimulated with either TLR agonist or $20 \%$ patient plasma for 3-6 hours prior to harvesting cells for RNA extraction. In experiments using TLR-expressing adherent cell lines, cells were seeded at $1-2 \times 10^{5}$ cells/well of a 48-well plate, rested in RPMI 1640 overnight, and then exposed to either TLR agonists or $20 \%$ patient plasma for the indicated amount of time. Following stimulation, total RNA was extracted (RNeasy Kit; QIAGEN). Exposure to $20 \%$ of a single lot of fetal bovine plasma was used as a negative control stimulus. For ex vivo cytokine detection, RNA was extracted upon immediate thawing of cryopreserved PBMCs using Trizol reagent per the manufacturer's recommendations (Invitrogen).

$1 \mu \mathrm{g}$ of total RNA from each sample served as the template to synthesize $50 \mu \mathrm{l}$ of cDNA, using TaqMan Reverse Transcription Reagents (Applied Biosystems), with the following reaction conditions: 10 minutes at $25^{\circ} \mathrm{C}$, then 30 minutes at $48^{\circ} \mathrm{C}$, and finally 5 minutes at $95^{\circ} \mathrm{C}$. Subsequently, cytokine and chemokine expression were amplified in a $25 \mu \mathrm{l}$ qPCR reaction containing the following: $2 \mu \mathrm{l}$ cDNA, $12.5 \mu \mathrm{l} 2 \times$ SYBR Green Master Mix (Applied Biosystems), and $500 \mathrm{nM}$ of gene-specific sense and anti-sense primers on a qPCR machine (7500 Fast Real-Time PCR System; Applied Biosystems). The amplification conditions were as follows: 2 minutes at $50^{\circ} \mathrm{C}, 10$ minutes at $95^{\circ} \mathrm{C}$, followed by 40 cycles of 15 seconds at $95^{\circ} \mathrm{C}$, and 1 minute at $60^{\circ} \mathrm{C}$. Emitted fluorescence for each reaction was measured during the annealing/extension phase, and amplification plots were analyzed using 7500 Fast software (Applied Biosystems). Relative quantification of gene expression was normalized against the housekeeping gene GAPDH. Data from relative induction of cytokine expression by cell subpopulations was visualized as heat maps using the JColorGrid JavaScript module (54).

Isolation of ICs and treatment of plasma with nucleases and proteases. ICs were isolated from patient plasma using the Melon Gel IgG Spin Purification Kit (Pierce) per the manufacturer's instructions. To test the role of nucleic acids in the immunostimulatory activity of test plasma, $20 \mu \mathrm{l}$ patient plasma or ICs 
DLI responders PBMCs
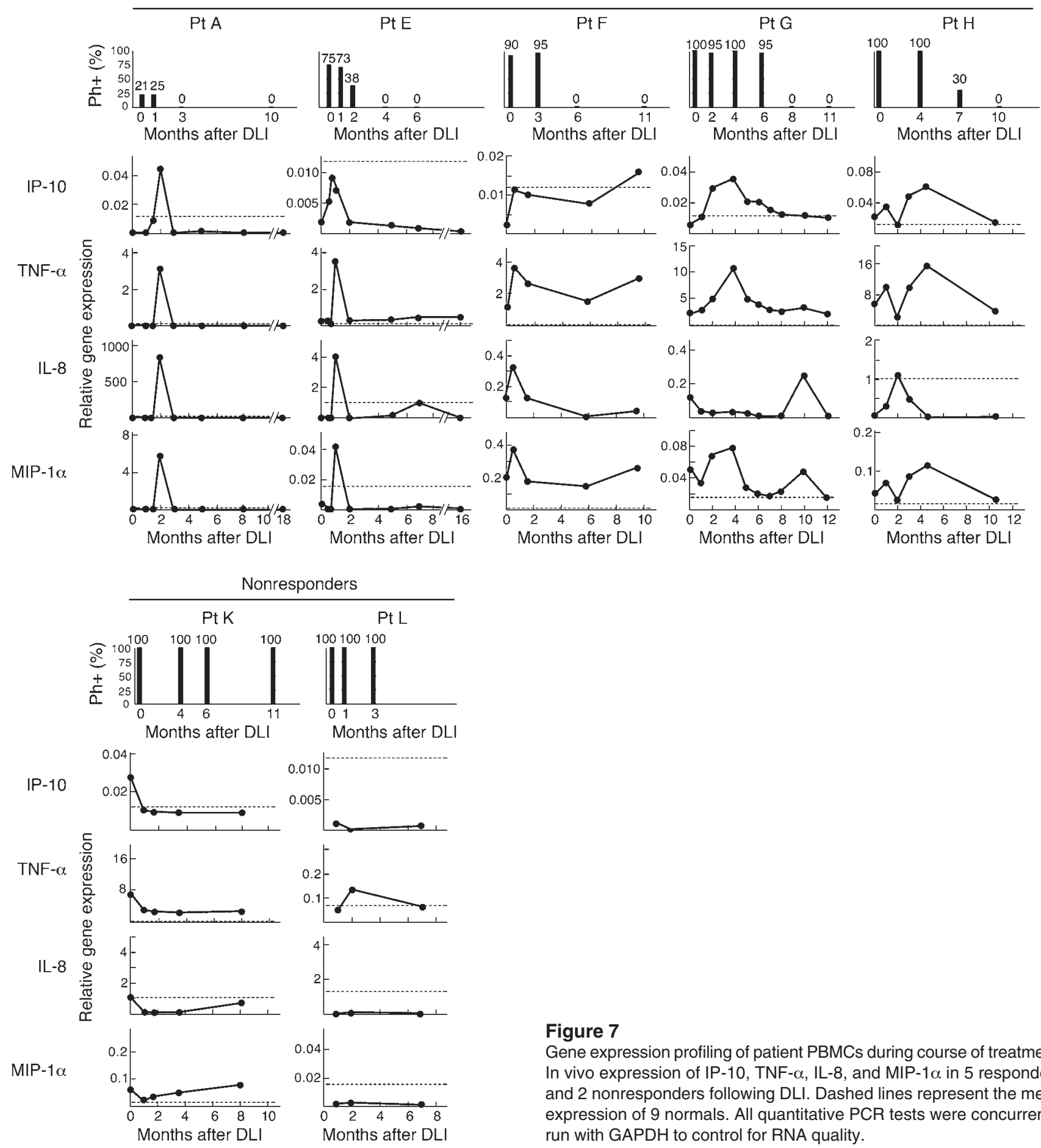

were treated with 20 units of DNase (Ambion) or 5 units of RNase (Promega) for 30 minutes at room temperature before stimulation of cells. Protease treatments of test plasma included incubation with $20 \mu \mathrm{l}$ of immobilized papain (Pierce) or $20 \mu$ l of immobilized pepsin (Pierce) at room temperature, prior to stimulation of cells and subsequent RNA extraction (described above).

In some experiments, CML66-containing ICs were used to stimulate cells. These complexes were generated from overnight incubation with $2 \mu \mathrm{g}$ of mouse anti-CML66 monoclonal antibody (22F; IgG1, $\kappa ; 1 \mu \mathrm{g} / \mathrm{ml}$ ) (22) or

Figure 7

Gene expression profiling of patient PBMCs during course of treatment. In vivo expression of IP-10, TNF- $\alpha$, IL-8, and MIP- $1 \alpha$ in 5 responders and 2 nonresponders following DLI. Dashed lines represent the mean expression of 9 normals. All quantitative PCR tests were concurrently run with GAPDH to control for RNA quality.

isotype control antibodies (anti-CD3, Coulter; or anti-actin, Sigma-Aldrich) with $500 \mu \mathrm{g}$ of $\mathrm{K} 562$ cell lysate (ATCC) at $4{ }^{\circ} \mathrm{C}$, with rotation. Lysates were generated through 3 rounds of freeze/thaw (55). CML66 antigen/antibody complexes were immunomagnetically isolated using Protein $\mathrm{G}$ microbeads (Miltenyi Biotec), in which $50 \mu$ l of PBS-washed microbeads were combined with K562 lysate/ $22 \mathrm{~F}$ complexes on ice for 60 minutes. ICs were eluted from immunomagnetic columns using $2 \mathrm{ml}$ of PBS, and 300-500 $\mu \mathrm{l}$ of eluant was used per stimulation. RNA was then extracted as described above. 
A

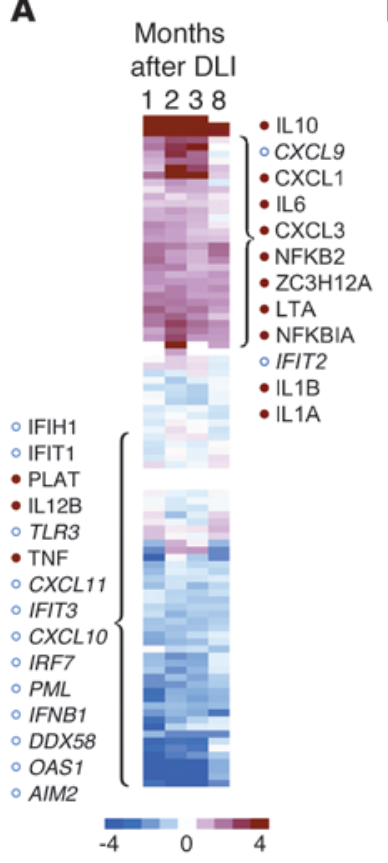

B
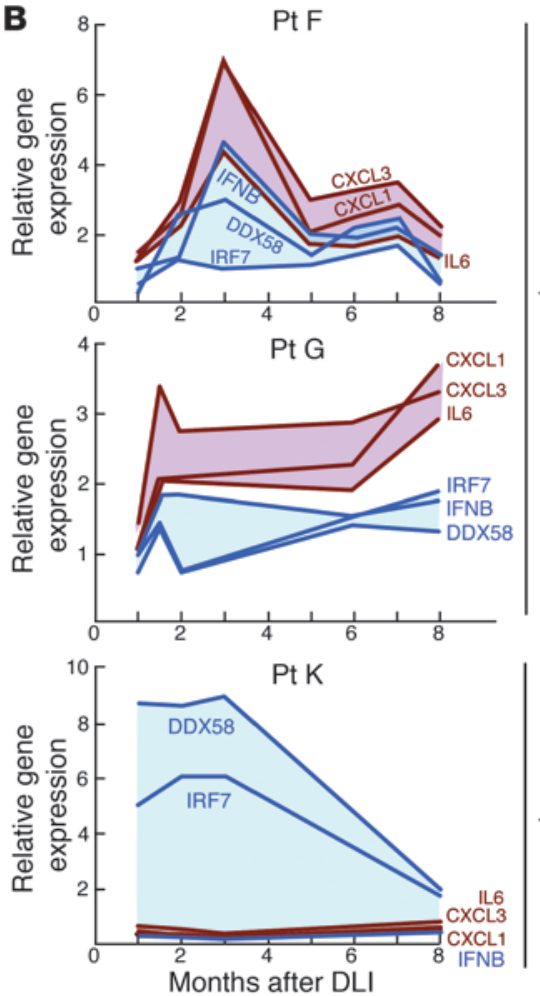

\section{Figure 8}

Gene expression profiling of patient PBMCs during course of treatment. (A) PBMCs from patient A were collected before treatment and at 1, 2, 3, and 8 months following treatment. mRNA at each time point was quantified using NanoString. The $\log _{2}$ fold changes relative to the pretreatment time point were hierarchically clustered and are displayed (red, induced; blue, repressed; white, unchanged). From stimulation experiments with purified innate immune ligands (data not shown), genes are classified into either the inflammatory/bacterial (filled red dots) or anti-viral (open blue circles, italic) response programs. Raw data and $\log _{2}$ fold data for the full set of 86 genes are provided in Supplemental Tables 2 and 3, respectively. (B) From the NanoString discovery set, we selected 3 inflammatory pathway genes (CXCL1, CXCL3, IL6, in red) and 3 viral pathway genes (DDX58, IRF7, IFNB, blue). By measuring quantitative gene expression of these 6 genes, we observed results consistent with the NanoString findings: that 2 of 2 independent responders are detected and confirmed from mRNA extracted from banked patient PBMCs (2 DLI responders and $1 \mathrm{DLI}$ nonresponder) by qRT-PCR.
To visualize nucleic acid in blood plasma of study subjects, $20-50 \mu \mathrm{l}$ of plasma was diluted with water to a total volume of $100 \mu \mathrm{l}$ and mixed with an equal volume of phenol-chloroform. The aqueous layer was precipitated with $200 \mu \mathrm{l}$ of $100 \%$ ethanol, resuspended in $30 \mu \mathrm{l}$ of water, and loaded on a $1.0 \%$ agarose gel that was stained with ethidium bromide. To visualize nucleic acid associated with plasma-derived ICs, 20-50 $\mu$ l plasma of study subjects was diluted with PBS to a total volume of $300 \mu$ land incubated with $30 \mu \mathrm{l}$ Protein $\mathrm{G}$ sepharose beads (Invitrogen) at $4^{\circ} \mathrm{C}$ for 2 hours. The ICs were subsequently heat disassociated from the beads $\left(65^{\circ} \mathrm{C}\right.$ for 5 minutes) after washing the beads 3 times with $0.1 \%$ Triton X-100/PBS and directly loaded onto $1.0 \%$ agarose gels that were stained with GelRed (Biotium). In a similar fashion, to detect nucleic acid associated with CML66 ICs, $3 \mathrm{mg}$ of K562 freeze-thaw cell lysate was immunoprecipitated with $2 \mu \mathrm{g}$ of antiCML66 antibody (or control $\alpha$-actin antibody) and $30 \mu$ Protein G sepharose beads for 2 hours at $4^{\circ} \mathrm{C}$. The complex was disassociated from beads by heating at $65^{\circ} \mathrm{C}$ for 5 minutes, and DNA in the complex was phenol-chloroform extracted, with the aqueous material ethanol precipitated.

Gene expression measurement by NanoString $n$ Counter. Details on the NanoString nCounter system have been previously presented in full (56). A CodeSet was designed to broadly capture transcriptional changes that occur during activation of the innate immune system: 86 genes were selected to represent the response of human monocyte-derived DCs to infection with E. coli or influenza PR8 (24), and 9 genes were added as controls whose expression remains steady during infection. For sample preparation, 100 ng mRNA was hybridized for 16 hours with the CodeSet and loaded into the nCounter prep station followed by imaging and quantification using the nCounter Digital Analyzer. nCounter data were first normalized to the average value of the NanoString spike-in probes to control for slight differences in hybridization efficiency. These data were then normalized to the average value of our 9 chosen control genes (GAPDH, FAM127A, CIAPIN1, MINK1, EIF5A, CEP350, TREX1, TLR4, CUGBP1). Gene expression of a series of upregulated or downregulated genes discovered by NanoString (CXCL1,
CXCL3, IL6, DDX58, IFNB1, and IRF7) was measured in independent patient PBMC RNA by qRT-PCR (Taqman Gene Expression Assays; Applied Biosystems) using a 7500 Fast Real-time PCR Cycler (Applied Biosystems). Genespecific transcript expression was measured relative to GAPDH.

Statistics. Comparisons of plasma cytokine expression between DLI responders and nonresponders or imatinib-treated patients were calculated using the Wilcoxon's rank sum test, with no correction for multiple comparisons and with all $P$ values reported as 2 sided. $P$ values less than 0.05 were considered significant.

\section{Acknowledgments}

We acknowledge expert technical assistance from Naa Lokko and Sean McDonough, and helpful suggestions from Joosang Park and Jonathan Duke-Cohan. We are also appreciative of the generous support from the Dana-Farber Cancer Institute (DFCI) Pasquarello Tissue Bank and from the DFCI clinical transplant teams. C.J. Wu acknowledges support from the Department of Defense (W81XWH-07-1-0080), the Miles and Eleanor Shore Award, the National Cancer Institute (5R21CA115043-2), and the Claudia Adams Barr Program in Cancer Research. C.J. Wu also received the Early Career Physician-Scientist Award of the Howard Hughes Medical Institute and is a Damon-Runyon Clinical Investigator supported (in part) by the Damon-Runyon Cancer Research Foundation (CI-38-07).

Received for publication November 30, 2010, and accepted in revised form January 19, 2011.

Address correspondence to: Catherine J. Wu, Dana-Farber Cancer Institute, Harvard Institutes of Medicine, Room 416, 77 Avenue Louis Pasteur, Boston, Massachusetts 02115, USA. Phone: 617.632.5943; Fax: 617.632.3351; E-mail: cwu@partners.org. 
1. Wu CJ, Ritz J. Induction of tumor immunity following allogeneic stem cell transplantation. $A d v$ Immunol. 2006;90:133-173.

2. Lampert IA, Moore RH, Huby R, Cohen J. Observations on the role of endotoxin in graft-versus-host disease. Prog Clin Biol Res. 1988;272:351-359.

3. Iwasaki A, Medzhitov R. Toll-like receptor control of the adaptive immune responses. Nat Immunol. 2004;5(10):987-995.

4. Savarese E, et al. Requirement of Toll-like receptor 7 for pristane-induced production of autoantibodies and development of murine lupus nephritis. Arthritis Rheum. 2008;58(4):1107-1115

5. Kelly-Scumpia KM, et al. In vivo adjuvant activity of the RNA component of the Sm/RNP lupus autoantigen. Arthritis Rheum. 2007;56(10):3379-3386.

6. Groom JR, et al. BAFF and MyD88 signals promote a lupuslike disease independent of T cells. $J$ Exp Med. 2007;204(8):1959-1971

7. Marshak-Rothstein A. Toll-like receptors in systemic autoimmune disease. Nat Rev Immunol. 2006; 6(11):823-835.

8. Christensen SR, Shupe J, Nickerson K, Kashgarian M, Flavell RA, Shlomchik MJ. Toll-like receptor 7 and TLR9 dictate autoantibody specificity and have opposing inflammatory and regulatory roles in a murine model of lupus. Immunity. 2006; 25(3):417-428

9. Lau CM, et al. RNA-associated autoantigens activate $B$ cells by combined B cell antigen receptor/ Toll-like receptor 7 engagement. J Exp Med. 2005; 202(9):1171-1177.

10. Means TK, Latz E, Hayashi F, Murali MR, Golenbock DT, Luster AD. Human lupus autoantibody-DNA complexes activate DCs through cooperation of CD32 and TLR9. J Clin Invest. 2005;115(2):407-417.

11. Herlands RA, Christensen SR, Sweet RA, Hershberg U, Shlomchik MJ. T cell-independent and toll-like receptor-dependent antigen-driven activation of autoreactive B cells. Immunity. 2008;29(2):249-260.

12. Vollmer J. CPG motifs to modulate innate and adaptive immune responses. Int Rev Immunol. 2006 ; 25(3-4):125-134.

13. Vollmer J, et al. Immunopharmacology of CpG oligodeoxynucleotides and ribavirin. Antimicrob Agents Chemother. 2004;48(6):2314-2317.

14. Kolb HJ, et al. Donor leukocyte transfusions for treatment of recurrent chronic myelogenous leukemia in marrow transplant patients. Blood. 1990; 76(12):2462-2465.

15. Alyea EP, et al. Toxicity and efficacy of defined doses of CD4(+) donor lymphocytes for treatment of relapse after allogeneic bone marrow transplant. Blood. 1998;91(10):3671-3680.

16. Wu CJ, et al. Detection of a potent humoral response associated with immune-induced remission of chronic myelogenous leukemia. J Clin Invest. 2000; 106(5):705-714.

17. Zhang W, et al. Graft-versus-leukemia antigen CML66 elicits coordinated B and T cell immunity after donor lymphocyte infusion. Clin Cancer Res. 2010;16(10):2729-2739.

18. Latz E, et al. TLR9 signals after translocating from the ER to CPG DNA in the lysosome. Nat Immunol. 2004;5(2):190-198.

19. Wu CJ, et al. Graft-versus-leukemia target antigens in chronic myelogenous leukemia are expressed on myeloid progenitor cells. Clin Cancer Res. 2005; 11(12):4504-4511.

20. Biernacki MA, et al. Efficacious immune therapy in chronic myelogenous leukemia (CML) recognizes antigens that are expressed on CML progenitor cells. Cancer Res. 2010;70(3):906-915.

21. Wang Q, et al. RNA interference targeting CML66, a novel tumor antigen, inhibits proliferation, invasion and metastasis of HeLa cells. Cancer Lett. 2008; 269(1):127-138.

22. Yang XF, et al. CML66, a broadly immunogenic tumor antigen, elicits a humoral immune response associated with remission of chronic myelogenous leukemia. Proc Natl Acad Sci US A. 2001;98(13):7492-7497.

23. Amit I, et al. Unbiased reconstruction of a mammalian transcriptional network mediating pathogen responses. Science. 2009;326(5950):257-263.

24 . Huang $Q$, et al. The plasticity of dendritic cell responses to pathogens and their components. Science. 2001; 294(5543):870-875.

25. McGettrick AF, O'Neill LA. Toll-like receptors: key activators of leucocytes and regulator of haematopoiesis. Br J Haematol. 2007;139(2):185-193.

26. Durakovic N, et al. Factors governing the activation of adoptively transferred donor T cells infused after allogeneic bone marrow transplantation in the mouse. Blood. 2007;109(10):4564-4574.

27. Taylor PA, et al. TLR agonists regulate alloresponses and uncover a critical role for donor APCs in allogeneic bone marrow rejection. Blood. 2008; 112(8):3508-3516.

28. Chakraverty $\mathrm{R}$, et al. The host environment regulates the function of CD8+ graft-versus-host-reactive effector cells. JImmunol. 2008;181(10):6820-6828.

29. She K, et al. Altered Toll-like receptor 9 responses in circulating B cells at the onset of extensive chronic graft-versus-host disease. Biol Blood Marrow Transplant. 2007;13(4):386-397.

30. Datta SK, et al. A subset of Toll-like receptor ligands induces cross-presentation by bone marrow-derived dendritic cells. J Immunol. 2003;170(8):4102-4110.

31. Heit A, Huster KM, Schmitz F, Schiemann M, Busch DH, Wagner H. CpG-DNA aided cross-priming by cross-presenting B cells. J Immunol. 2004; 172(3):1501-1507.

32. Maurer T, et al. CPG-DNA aided cross-presentation of soluble antigens by dendritic cells. Eur J Immunol. 2002;32(8):2356-2364.

33. Pasare C, Medzhitov R. Toll pathway-dependent blockade of CD4+CD25+ T cell-mediated suppression by dendritic cells. Science. 2003; 299(5609):1033-1036.

34. Pasare C, Medzhitov R. Toll-dependent control mechanisms of CD4 T cell activation. Immunity. 2004; 21(5):733-741.

35. Schwarz K, et al. Role of Toll-like receptors in costimulating cytotoxic T cell responses. Eur IImmunol. 2003; 33(6): $1465-1470$.

36. Pasare C, Medzhitov R. Control of B-cell responses by Toll-like receptors. Nature. 2005;438(7066):364-368.

37. Goforth R, et al. Immune stimulatory antigen loaded particles combined with depletion of regulatory T-cells induce potent tumor specific immunity in a mouse model of melanoma. Cancer Immunol Immunother. 2009;58(4):517-530.

38. Barr TA, Brown S, Ryan G, Zhao J, Gray D. TLRmediated stimulation of APC: Distinct cytokine responses of B cells and dendritic cells. Eur J Immunol. 2007;37(11):3040-3053.

39. Ketloy C, et al. Expression and function of Toll-like receptors on dendritic cells and other antigen presenting cells from non-human primates. Vet Immunol Immunopathol. 2008;125(1-2):18-30.

40. Singh NJ, Cox M, Schwartz RH. TLR ligands differentially modulate $\mathrm{T}$ cell responses to acute and chronic antigen presentation. J Immunol. 2007; 179(12):7999-8008.

41. Anker P, Mulcahy H, Chen XQ, Stroun M. Detection of circulating tumour DNA in the blood (plasma/ serum) of cancer patients. Cancer Metastasis Rev. 1999;18(1):65-73.

42. Fournie GJ, et al. Plasma DNA as a marker of cancerous cell death. Investigations in patients suffering from lung cancer and in nude mice bearing human tumours. Cancer Lett. 1995;91(2):221-227.

43. Leon SA, Shapiro B, Sklaroff DM, Yaros MJ. Free DNA in the serum of cancer patients and the effect of therapy. Cancer Res. 1977;37(3):646-650.

44. Giacona MB, Ruben GC, Iczkowski KA, Roos TB, Porter DM, Sorenson GD. Cell-free DNA in human blood plasma: length measurements in patients with pancreatic cancer and healthy controls. Pancreas. 1998;17(1):89-97.

45. Tesniere A, et al. Immunogenic cancer cell death: a key-lock paradigm. Curr Opin Immunol. 2008; 20(5):504-511.

46. Zitvogel L, Apetoh L, Ghiringhelli F, Andre F, Tesniere $\mathrm{A}$, Kroemer $\mathrm{G}$. The anticancer immune response: indispensable for therapeutic success? J Clin Invest. 2008;118(6):1991-2001.

47. Aliyari R, Ding SW. RNA-based viral immunity initiated by the Dicer family of host immune receptors. Immunol Rev. 2009;227(1):176-188.

48. Takeshita F, Ishii KJ. Intracellular DNA sensors in immunity. Curr Opin Immunol. 2008;20(4):383-388.

49. Yoneyama M, Fujita T. RNA recognition and signal transduction by RIG-I-like receptors. Immunol Rev. 2009;227(1):54-65.

50. Marina $\mathrm{O}$, et al. Serologic markers of effective tumor immunity against chronic lymphocytic leukemia include nonmutated B-cell antigens. Cancer Res. 2010; 70(4):1344-1355.

51. Rozkova D, et al. Toll-like receptors on B-CLL cells: Expression and functional consequences of their stimulation. Int J Cancer. 2010;126(5):1132-1143.

52. Ghosh TK, Mickelson DJ, Solberg JC, Lipson KE, Inglefield JR, Alkan SS. TLR-TLR cross talk in human PBMC resulting in synergistic and antagonistic regulation of type- 1 and 2 interferons, IL-12 and TNFalpha. Int Immunopharmacol. 2007;7(8):1111-1121.

53. Zheng R, et al. Paired Toll-like receptor agonists enhance vaccine therapy through induction of interleukin-12. Cancer Res. 2008;68(11):4045-4049.

54. Joachimiak MP, Weisman JL, May B. JColorGrid: software for the visualization of biological measurements. BMC Bioinformatics. 2006;7:225.

55. Herr W, Ranieri E, Olson W, Zarour H, Gesualdo L, Storkus WJ. Mature dendritic cells pulsed with freezethaw cell lysates define an effective in vitro vaccine designed to elicit EBV-specific CD4(+) and CD8(+) T lymphocyte responses. Blood. 2000;96(5):1857-1864.

56. Geiss GK, et al. Direct multiplexed measurement of gene expression with color-coded probe pairs. Nat Biotechnol. 2008;26(3):317-325. 